Momentum Investing: The Case of High-Tech IPOs

Sanjiv Jaggia

Satish Thosar 


\title{
Momentum Investing: The Case of High-Tech IPOs
}

\begin{abstract}
:
We document significant momentum effects in the high-tech IPO aftermarket beyond the initial (underpricing) run-up. Cumulative market-adjusted returns (CMARs) reveal a striking pattern. A local peak of just over 10 percent is reached around 20 trading days post-IPO coinciding with the expiry of the "quiet period". A global peak (of about 33 percent) is reached after 105 trading days. The CMAR decays fairly rapidly thereafter possibly in anticipation of the expiry of the six-month lockup period. Further, we find strong evidence of a linkage between technical ex-ante observable variables and the momentum build-up. We conjecture that visceral factors may at least partially underlie the investor behavior that gives rise to the bubble-like
\end{abstract} CMAR pattern. 


\section{Momentum Investing: The Case of High-Tech IPOs}

\section{Introduction:}

The profitability of momentum strategies is relatively well documented in the literature. Jegadeesh and Titman $(1993,2001)$ show that a naïve strategy that involves buying recent winners and shorting recent losers and holding the position for up to twelve months earns significant positive risk-adjusted returns. However cumulative returns begin to decay soon thereafter and in some cases turn negative for holding periods beyond a three-year period. These studies cover long sample periods and virtually all stocks listed on the major US exchanges and imply support for behavioral models developed in response to the mounting empirical evidence against market efficiency. ${ }^{1}$ These large scale studies of momentum effects contribute to our understanding of investor behavior and are therefore important, regardless of where one stands on the market efficiency debate. However, in our opinion there is also something to be gained from examining momentum 'in the small'.

Our study looks at momentum effects in a sample of 301 high-tech IPOs launched in 1998-99 measured over a six-month period. We feel that our sample choice is interesting and appropriate for a number of reasons. There has been a great deal of commentary in various outlets about post-IPO market dynamics. This includes the issue of flipping activity by investors who receive allocations at the offer price, price stabilization activity by underwriters, the initiation of coverage by analysts and the price effects at the expiry of the quiet and lock-up periods. ${ }^{2}$ Also, IPO underpricing was at its height during the technology bubble of the late 1990s

\footnotetext{
${ }^{1}$ See Daniel et al (1998), Barberis et al (1998) and Hong and Stein (1999).

${ }^{2}$ See Aggarwal $(2000,2003)$ on price stabilization and flipping respectively; Bradley et al (2003) on analyst coverage and the quiet period; Field and Hanka (2001) on lock-up expiration.
} 
(see Loughran and Ritter (2003)). Therefore we felt that a look at high-tech IPO aftermarket patterns was likely to be instructive and revealing at the possible cost of some generality. ${ }^{3}$

In a strictly rational setting, the market-adjusted return series in a post-IPO environment ought to be random. Let's assume that average initial underpricing is driven by economically sound reasons. ${ }^{4}$ Once this has been sorted out by the market and given the SEC rules about no new fundamental information release (or the requirement of a 'quiet period') for twenty-five calendar days, there is no obvious rationale for a systematic direction in post-IPO returns.

However, we find significant evidence of momentum beyond the initial (underpricing) run-up. Cumulative market-adjusted returns (CMAR) reveal a striking pattern. A local peak of just over 10 percent is reached around 20 trading days post-IPO coinciding with the expiry of the 'quiet period'. A global peak (of about 33 percent) is reached after 105 trading days. The CMAR decays fairly rapidly thereafter possibly in anticipation of the expiry of the six-month lockup period. The results are especially compelling when the sample is segregated on the basis of the initial (Day 1) market reaction. Not only do the above momentum patterns prevail for each subsample, the CMAR peak is significantly higher for firms who fare well on Day 1. Although the initial market reaction seems to trigger aftermarket momentum, its effect is short lived. We implement a model that relates the probability of crossing a desired return threshold to momentum, fundamental, and IPO contract-specific variables. We show that trading on Day 1 momentum signals achieves considerable separation in the expected probability of crossing the threshold. We conjecture that momentum investing in the post-IPO context is driven at least partially by visceral factors.

\footnotetext{
${ }^{3}$ Jaggia and Thosar (2003) employ a similar sample to formulate and test hypotheses based on the Daniel et al (1998) investor overconfidence and self-attribution bias theory.

${ }^{4}$ These could be the Rock (1986) winner's curse argument, the Benveniste and Spindt (1989) information revelation story or perhaps more relevant in the context of our sample: the changes in insider incentives suggested by Ljungqvist and Wilhelm (2003).
} 
The rest of the paper is organized as follows. In Section 2, we present research questions and detailed discussion of our results. Section 3 contains concluding comments.

\section{Research Questions and Data Analysis:}

Our primary sample was drawn from ipo.com to identify all high-tech IPO firms from January 1, 1998 through October 30, 1999. Daily open prices for each of the 301 firms in the sample and the corresponding NASDAQ index level are downloaded for 125 trading days (approximately six months) beyond the IPO date from yahoo finance and edreyfus.com. ${ }^{5}$ The cumulative market-adjusted return (CMAR) is calculated as:

$$
C M A R_{i t}=\frac{P_{i t} / P_{i 1}}{P_{m t} / P_{m 1}}-1
$$

$\mathrm{P}_{\text {it }}$ represents the Day t open price of the $\mathrm{i}^{\text {th }}$ firm and $\mathrm{P}_{\mathrm{mt}}$ is the corresponding market (Nasdaq) index and $t$ refers to the time from the IPO date.

At the outset, we simply graph the equally-weighted portfolio CMAR in event time for 125 trading days (see Figure 1). ${ }^{6}$ We choose day 2 as the starting point because we wish to exclude the initial (underpricing) spike and Day 1 effects that might serve to explain post-IPO market patterns. The shape of the graph is rather striking. There appears to be at least prima facie evidence of momentum investing. To our mind, at least two broad research questions arise from observing this CMAR pattern:

1) What economic, institutional and/or behavioral forces underlie momentum investing in the high-tech IPO context?

\footnotetext{
${ }^{5}$ We decided on a six-month window to avoid any complicating biases arising from the market correction in mid 2000. Further this short observation interval of six-months precludes post-IPO events such as mergers, seasoned offerings.

${ }^{6}$ We remind the reader that CMAR represents market-adjusted but not risk-adjusted cumulative returns. Risk adjustment using traditional single- or multi-factor market models is not feasible in an IPO event context.
} 
2) Can this post-IPO momentum be explained and/or exploited using ex-ante observable factors?

The first research question regarding the CMAR pattern in Figure 1 is difficult to address directly. Fortunately, there is an emerging body of literature dealing with IPO aftermarket dynamics that one could draw upon to make some inferences. For instance, the local peak of 10 percent that we observe at 20 trading days post-IPO coincides with the expiry of the 'quiet period' imposed by the SEC. ${ }^{7}$ Bradley et al (2003) show that most of the aftermarket abnormal returns for IPO firms, where analyst coverage is initiated immediately, occurs in the run-up to the expiry of the quiet period (see their Figure 1, page 13). Likewise, in our sample the CMAR jumps by 7.3 percent between post-IPO trading day 13 and 20 even though we do not control for analyst coverage. It is reasonable to assume that underwriters engage in price stabilization activities (of which inducing wider analyst coverage may be an informal part) in the days following the IPO and for our sample at least, they seem to have considerable success. ${ }^{8}$

There is a drop-off in the CMAR from just over 10 percent to 5.5 percent during the 10 trading days after the quiet period expiration, possibly due to delayed flipping. However, it does not take long for the momentum to build again. After oscillating in the 6-7 percent range for another 20 or so trading days, the CMAR begins to trend sharply upward reaching a peak of 33 percent on trading day 105. The CMAR declines rapidly beyond this peak as we approach the six-month mark or the outer limit of our observation period. The most plausible explanation for the decline is that the market is recognizing the imminent expiration of the standard lock-up period and the probable onset of insider selling. A number of papers have documented high

\footnotetext{
${ }^{7}$ Under SEC regulations, firms and underwriters can make statements of fact but not issue forwardlooking opinions for a period of 25 calendar days (recently extended to 40) after the IPO date. ${ }^{8}$ Aggarwal (2000) has shown that rather than posting a stabilizing bid, underwriters engage in less transparent price support activities, which includes penalizing early flipping.
} 
volumes and significantly negative returns on lock-up expiration (see, for example, Field and Hanka (2001)).

We use regression analysis to address the second research question whether post-IPO momentum is explained using ex-ante observable factors. A number of momentum, fundamental and IPO contract-specific explanatory variables are used for the analysis. Our choice of variables may appear to be somewhat ad hoc but this goes with the territory of exploratory research in general (i.e., the anomalies literature) and momentum studies in particular. We believe that our study has generated interesting and provocative results, which are discussed below.

Four momentum variables are included. Percentage Price Change, the change from the offer price to the open price, represents the initial underpricing (or overpricing). One could view the offer price as book value and the open price as market value; thus this variable could be loosely construed as a market/book factor. If this variable is a risk factor, we would expect a negative effect on post-IPO returns; alternatively it could also be a momentum factor in which case it would have a positive sign. Day 1 Adjusted Return is hypothesized as a momentum variable representing the market-adjusted return on the first day of trading and Day 1 Volatility (High/Low) captures immediate post-IPO investor uncertainty. Day 1 Volume (Volume/Number of Shares) serves as a proxy for investor activity. If it is viewed as a crude flipping indicator, it should have a negative impact; alternatively it could be a second-order momentum variable.

Fundamental variables include Net Income/Revenue, net income divided by revenue in the pre-IPO year, representing a proxy for firm quality. Log Revenue is included because a profitability variable may not be relevant in a high-tech IPO context. Many analysts had discarded traditional valuation metrics during the technology boom of the late 1990s. Age before the IPO, the number of years from the date the firm was incorporated to the IPO date, represents 
a second-order proxy for firm quality. Log Offer Size, offer price multiplied by the number of shares sold in the IPO, is a proxy for size and a potential risk factor.

For IPO contract-specific variables, Underwriter Reputation takes value 1 if the CarterManaster rank exceeds 7; 0 otherwise. It has been used in previous work to explain underpricing. If accurate pricing goes together with underwriter reputation, we expect post-IPO distortions to be reduced. Green Shoe Dummy is a dummy variable for a green shoe provision in the IPO contract. This provision gives the underwriter the option to purchase additional shares at the offer price to cover over allotments. It also potentially serves as a post-IPO price stabilization mechanism. Internet Dummy takes value 1 if the IPO firm belongs either to the Internet services or Internet software sectors. We include this variable to capture the sentiment that internet related IPOs tended to be talked up in business press.

The data sources for the above variables are ipo.com, FISonline, Hoovers.com, and Carter, Dark and Singh (1998). For descriptive statistics, we ordered each variable and split it up into four equal quartile segments (see Table 1). Means are calculated for all observations and for each of the four segments. Firms appear to be fairly homogenous with respect to fundamental variables, especially revenue and offer size. However, the initial underpricing and market reaction variables are remarkably different across quartile segments.

We start the analysis with an OLS regression with the six-month CMAR as the dependent variable and all explanatory variables as defined above (see column 2 of Table 2). Day 1 adjusted return exerts a positive influence on the six-month CMAR but is only weakly significant. The only variables that are strongly significant are: underwriter reputation and the Internet identification. We interpret this to mean that, as the CMAR graphs suggest, momentum investing begins to wane before the six-month mark is reached. Therefore, any investment 
strategy built around ex-ante technical factors involves cashing out either once a certain threshold is reached or in any case no later than around 105 trading days after the IPO.

Therefore, following Jaggia and Thosar (2003), we define an event when the CMAR for a firm exceeds a 25 (or 50) percent threshold at any time over the six-month observation period. These market-adjusted return thresholds are set arbitrarily but high enough to reflect momentum investing. Recall that we specifically exclude the initial run-up (offer price to day 0 open price) and the day 1 return (day 0 open to day 1 open prices) from the CMAR calculation; these may reflect the incorporation of information not contained in the prospectus or other public domain information sources.

The regression results of a logit regression for the $25 \%$ and $50 \%$ thresholds are reported in columns 3 and 4 of Table 2. None of the fundamental proxies: pre-IPO profitability, revenue, age or size is significant and this is not necessarily surprising because we expect this information to be incorporated in the offer and/or initial market prices. The underwriter reputation variable appears to have a significantly positive impact on post-IPO momentum. This makes sense if the efficacy of price stabilization activity or the potency of analyst recommendations is tied to underwriter prestige. There is mounting evidence that analyst recommendations especially during the late 1990s bubble period were highly optimistic. Also, analysts tend to initiate coverage with a 'buy' or 'strong buy' recommendation (Bradley et al (2003)). It has been suggested that IPO firms trade off underpricing for favorable analyst coverage (Loughran and Ritter (2003)). We also find that for the 50 percent threshold, identification as an Internet firm within the high-tech context contributes to momentum.

Initial underpricing (our percentage price change variable) has a significantly negative influence on post-IPO momentum. It appears that the market views underpricing as a risk factor 
rather than a momentum signal. Perhaps our most intriguing finding is that the day 1 adjusted return is a strongly positive predictor of momentum. In order to gauge how useful the factors, identified as significant by our logit model, were in a speculative investment context, we carry out sensitivity analyses on these factors. The results are reported in Table 3. For example, if all other factors are considered at their overall mean values but the day 1 adjusted return is evaluated sequentially at the means of four quartile segments (see Table 1), our model predicts the expected probability of reaching the 25 percent threshold as 55.9 percent for the bottom quartile versus 75.4 percent for the top quartile - a not inconsiderable separation.

Sensitivity results along similar lines are reported for: percentage price change, day 1 volume and underwriter reputation. It is worth noting that day 1 volume, which we categorized as a potential second-order momentum variable, is significant only for the 50 percent threshold. Apparently high volume on day 1 is not a deterrent to new investors despite claims in the business press of flipping activity by those allocated shares in the IPO. Aggarwal (2003) shows that contrary to popular belief initial flipping volume is quite modest.

For further raw analysis of CMAR, we sort our sample on the basis of day 1 adjusted return and form four equally-weighted event time CMAR portfolios for 125 trading days based on quartile segments (see graphs in Figure 2). The first point to note is that the peaks and troughs for the four portfolios largely track each other and bear a close resemblance to the graph for the total sample shown in Figure 1. ${ }^{9}$ The second point is that investors can benefit a great deal if they make their move after observing the day 1 return. All four CMAR series reach their global peaks at approximately the same time: 105 trading days for the top quartile segment (S4)

\footnotetext{
${ }^{9}$ This is also an informal robustness check of in-sample integrity. Our investigation of momentum investing owes its rationale to the CMAR pattern in Figure 1 and it is reassuring that this pattern repeats in sub-samples.
} 
and 112 trading days for the bottom quartile segment (S1). But the difference in magnitude is startling: 53 percent for S4 versus only 15 percent for S1.

To summarize: the CMAR patterns (Figures 1 and 2) indicate the presence of momentum investing, the logit regression results imply that ex-ante technical factors such as the dayl adjusted return can be used to predict the momentum (defined as the probability of reaching a pre-specified return threshold) and the sensitivity analysis confirms that the separation between the probability estimates - say between the top and bottom quartile segments for a given factor is large enough to make a difference in devising a trading strategy.

\section{Concluding Comments:}

In this paper, we study the phenomenon of momentum investing using a relatively narrow sample of high-tech IPOs launched in the late 1990s. Cumulative market-adjusted returns measured starting from day 2 after the IPO and tracked for six-months reveal a pronounced bubble-like pattern. Our overall findings are largely consistent with various recent studies that have examined IPO aftermarket dynamics such as price effects at quiet period and lock-up expiration. Further analysis with a logit model demonstrates that technical factors observable exante have considerable power in terms of predicting the probability of exceeding pre-specified return thresholds.

Even in the context of our late 1990s sample period, the magnitude and pattern of the CMAR appears anomalous. It almost seems as if there was a bubble within a bubble and the place to look for an explanation is probably somewhere in the burgeoning literature on behavioral finance. ${ }^{10}$ We offer some conjectures about the kind of investor behavior that might give rise to the momentum effects we document without invoking the most widely cited

\footnotetext{
${ }^{10}$ See Barberis and Thaler (2003) for a useful survey.
} 
behavioral models in the finance literature ${ }^{11}$. We choose to do this not because we believe these models do not apply but simply to introduce a new flavor into the mix.

Loewenstein (2000) discusses the role of visceral factors in determining human behavior. In general, individuals are either in a 'hot' state, where emotions or visceral factors dominate, or a 'cold state' where decisions are guided by rational thought processes. The important psychological insight is the 'empathy gap' between hot and cold states. This means that individuals do not learn from mistakes made while in a hot state and are in a sense prone to repeat them. Loewenstein argues that visceral factors play a critical role in inter-temporal choice and may explain anomalous risk-taking behavior such as the simultaneous purchase of insurance and gambling.

We think it is plausible that visceral factors at least partially underlie momentum investing, which gives rise to bubble-like patterns. In an investment context: hyped-up analyst reports, enthusiastic but not necessarily informative coverage on TV channels, Internet chat rooms and bulletin boards, word of mouth etc. probably induce investors to switch from cold to hot states with predictable consequences for the late comers. Moreover, the so-called empathy gap ensures that even burned investors are unlikely to learn from the experience.

We don't want to make too much of this line of reasoning. It is quite possible that these visceral factors affect only a small proportion of investors and a narrow range of stocks: microcaps, IPOs, takeover targets etc. In any case, it would be nearly impossible to test behavioral hypotheses directly from market data - controlled laboratory experiments may well be the most fruitful way to gain a deeper understanding of this type of investor behavior. And, if Loewenstein (and others) are right, it may not be enough for finance theorists to build models with dichotomies like: informed versus uniformed, over-confident versus conservative, news-

\footnotetext{
${ }^{11}$ See references in footnote 1, Delong et al (1990) and Shiller (1984).
} 
watchers versus trend-chasers. It may be necessary to model a schizophrenic investor who switches between hot and cold states. The hunt for a unified theory that would explain all the observed empirical anomalies seems destined to be a long one. 


\section{References:}

Aggarwal, R., 2000, Stabilization activities by underwriters after initial public offerings. Journal of Finance, 55, 1075-1103.

Aggarwal, R., 2003, Allocation of initial public offerings and flipping activity. Journal of Financial Economics, 68, 111-135.

Barberis, N., Shleifer, A., Vishny R., 1998. A model of investor sentiment. Journal of Financial Economics, 49, 307-343.

Barberis, N., Thaler, T., 2003. A survey of behavioral finance. In: Handbook of the Economics of Finance, edited by G. Constantinides, M. Harris and R. Stulz, North-Holland, Amsterdam.

Benveniste, L. M., Spindt, P.A., 1989. How investment bankers determine the offer price and allocation of new issues. Journal of Financial Economics, 24(2), 343-361.

Bradley, D. J., Jordan, B. D., Ritter, J.R., 2003. The quiet period goes out with a bang. Journal of Finance, 58 (1), 1-36.

Carter, R. B., Dark, F. H., Singh, A.K., 1998. Underwriter reputation, initial returns and the long-run performance of IPO stocks. Journal of Finance, 53(1), 285-311.

Daniel, K., Hirshleifer, D., Subrahmanyam, A., 1998. Investor psychology and security market under- and overreactions. Journal of Finance, 53, 1839-1886.

Delong, J.B., Shleifer, A., Summers, L., Waldmann, R.J., 1990. Positive feedback investment strategies and destabilizing rational speculation. Journal of Finance, 45, 375-395.

Field, L.C., Hanka, G., 2001. The expiration of IPO share lockups. Journal of Finance, 56 (2), 471-500.

Hong, H., Stein, J.C., 1999. A unified theory of underreaction, momentum trading and overreaction in asset markets. Journal of Finance, 54, 2143-2184.

Jaggia, S., Thosar, S., 2003. The medium-term aftermarket in high-tech IPOs: Patterns and implications. Journal of Banking and Finance, forthcoming.

Jegadeesh, N., Titman, S., 1993. Returns to buying winners and selling losers: Implications for stock market efficiency. Journal of Finance, 48, 65-91.

Jegadeesh, N., Titman S., 2001. Profitability of momentum strategies: An evaluation of alternative explanations. Journal of Finance, 56, 699-720. 
Ljungqvist, A., Wilhelm, W. J., 2003. IPO pricing in the dot-com bubble. Journal of Finance, 58 (2), 723-752.

Loughran, T., Ritter, J.R., 2003. Why has IPO underpricing changed over time? Unpublished manuscript.

Loewenstein, G., 2000. Emotions in economic theory and economic behavior. American Economic Review. 90 (2), 426-433.

Rock, K., 1986. Why new issues are underpriced. Journal of Financial Economics, 15, 187-212.

Shiller, R.A., 1984. Stock prices and social dynamics. The Brookings Papers on Economic Activity, 2, 457-498. 
Table 1. Overall and Quartile Segments Means of Variables

\begin{tabular}{lccccc}
\hline Parameters & All & S1 & S2 & S3 & S4 \\
\hline Percentage Price Change & 61.92 & -1.75 & 20.04 & 51.01 & 167.66 \\
Day 1 Adjusted Return & 5.28 & -15.22 & -3.17 & 4.96 & 32.73 \\
Day 1 Volatility (High/Low) & 31.04 & 8.88 & 19.99 & 30.67 & 62.90 \\
Day 1 Volume (Vol/\#Shares) & 1.27 & 0.20 & 0.87 & 1.50 & 2.44 \\
Net Income/Revenue & -1.77 & -6.24 & -1.10 & -0.31 & 0.42 \\
Log Revenue & 16.03 & 13.51 & 15.68 & 16.69 & 18.16 \\
Age & 5.33 & 1.31 & 3.15 & 4.72 & 11.65 \\
Log Offer Size & 17.94 & 16.96 & 17.71 & 18.07 & 18.96 \\
Underwriter Reputation & 0.80 & 0.20 & 1.00 & 1.00 & 1.00 \\
Green Shoe Dummy & 0.57 & 0.00 & 0.29 & 1.00 & 1.00 \\
Internet Dummy & 0.60 & 0.00 & 0.41 & 1.00 & 1.00 \\
\hline
\end{tabular}

For each variable, observations are ordered and split up into four equal quartile segments. Means are calculated for all observations and for each of the four segments, $S_{j}$. 
Table 2. Analysis of the 6-month Adjusted Returns and 25\% and 50\% thresholds

\begin{tabular}{|c|c|c|c|}
\hline Parameters & 6-month & $25 \%$ Threshold & $50 \%$ Threshold \\
\hline Constant & $\begin{array}{l}40.44 \\
(0.287)\end{array}$ & $\begin{array}{l}-0.471 \\
(-0.159)\end{array}$ & $\begin{array}{l}-1.791 \\
(-0.672)\end{array}$ \\
\hline Percentage Price Change & $\begin{array}{l}-0.08 \\
(-1.031)\end{array}$ & $\begin{array}{l}-0.003 * \\
(-2.053)\end{array}$ & $\begin{array}{l}-0.004^{*} \\
(-2.158)\end{array}$ \\
\hline Day 1 Adjusted Return & $\begin{array}{l}0.60 * * \\
(1.726)\end{array}$ & $\begin{array}{l}0.018^{*} \\
(2.362)\end{array}$ & $\begin{array}{l}0.016^{*} \\
(2.066)\end{array}$ \\
\hline Day 1 Volatility (High/Low) & $\begin{array}{l}-0.53 \\
(-1.635)\end{array}$ & $\begin{array}{l}-0.009 \\
(-1.141)\end{array}$ & $\begin{array}{l}-0.002 \\
(-0.322)\end{array}$ \\
\hline Day 1 Volume (Vol/\#Shares) & $\begin{array}{l}1.97 \\
(0.225)\end{array}$ & $\begin{array}{l}0.286 \\
(1.616)\end{array}$ & $\begin{array}{l}0.344^{*} \\
(2.045)\end{array}$ \\
\hline Net Income/Revenue & $\begin{array}{l}-4.26^{* *} \\
(-1.760)\end{array}$ & $\begin{array}{l}-0.071 \\
(-1.549)\end{array}$ & $\begin{array}{l}0.001 \\
(0.029)\end{array}$ \\
\hline Log Revenue & $\begin{array}{l}3.66 \\
(0.835)\end{array}$ & $\begin{array}{l}0.039 \\
(0.491)\end{array}$ & $\begin{array}{l}0.071 \\
(0.879)\end{array}$ \\
\hline Age & $\begin{array}{l}0.18 \\
(0.143)\end{array}$ & $\begin{array}{l}0.026 \\
(0.891)\end{array}$ & $\begin{array}{l}-0.000 \\
(-0.004)\end{array}$ \\
\hline Log Offer Size & $\begin{array}{l}-7.34 \\
(-0.829)\end{array}$ & $\begin{array}{l}-0.042 \\
(-0.234)\end{array}$ & $\begin{array}{l}-0.022 \\
(-0.130)\end{array}$ \\
\hline Underwriter Reputation & $\begin{array}{l}49.84 * \\
(2.863)\end{array}$ & $\begin{array}{l}0.839^{*} \\
(2.518)\end{array}$ & $\begin{array}{l}0.572 * * \\
(1.708)\end{array}$ \\
\hline Green Shoe Dummy & $\begin{array}{l}1.69 \\
(0.126)\end{array}$ & $\begin{array}{l}0.221 \\
(0.824)\end{array}$ & $\begin{array}{l}0.244 \\
(0.934)\end{array}$ \\
\hline Internet Dummy & $\begin{array}{l}29.77^{*} \\
(2.109)\end{array}$ & $\begin{array}{l}0.247 \\
(0.877)\end{array}$ & $\begin{array}{l}0.583^{*} \\
(2.100)\end{array}$ \\
\hline
\end{tabular}

Coefficient estimates with t-statistics in parentheses; * and ${ }^{* *}$ denote significance at 5 and 10 percent level respectively. A linear regression model is used to analyze 6-month returns and a logit model for the $25 \%$ and $50 \%$ threshold returns. All returns are calculated from Day 2. 
Table 3: Expected Probability of reaching the thresholds for Various Factors.

\begin{tabular}{|c|c|c|}
\hline Variable & 25\% Threshold & $50 \%$ Threshold \\
\hline Average & $64.88 \%$ & $53.21 \%$ \\
\hline \multicolumn{3}{|c|}{ Percentage Price Change } \\
\hline-1.75 & $69.09 \%$ & $58.78 \%$ \\
\hline 20.04 & $67.68 \%$ & $56.89 \%$ \\
\hline 51.01 & $65.62 \%$ & $54.17 \%$ \\
\hline 167.66 & $57.39 \%$ & $43.85 \%$ \\
\hline \multicolumn{3}{|c|}{ Day 1 Adjusted Return } \\
\hline-15.22 & $55.90 \%$ & $45.18 \%$ \\
\hline-3.17 & $61.27 \%$ & $49.89 \%$ \\
\hline 4.96 & $64.75 \%$ & $53.08 \%$ \\
\hline 32.73 & $75.37 \%$ & $63.62 \%$ \\
\hline \multicolumn{3}{|l|}{ Day 1 Volume } \\
\hline 0.20 & $57.64 \%$ & $44.04 \%$ \\
\hline 0.87 & $62.26 \%$ & $49.80 \%$ \\
\hline 1.50 & $66.38 \%$ & $55.19 \%$ \\
\hline 2.44 & $72.10 \%$ & $63.00 \%$ \\
\hline \multicolumn{3}{|c|}{ Underwriter Reputation } \\
\hline 1 & $68.59 \%$ & $56.03 \%$ \\
\hline 0 & $48.55 \%$ & $41.83 \%$ \\
\hline
\end{tabular}

The expected probability is calculated as $\frac{1}{1+\exp \left(-\sum \hat{\beta}_{j} \bar{x}_{j}\right)}$ where $\bar{x}^{\prime} s$ represents the quartile segment means of the indicated variable along with the overall means of all other variables. 
Figure 1. Cumulative Market Adjusted Returns in the 6-month post IPO Period

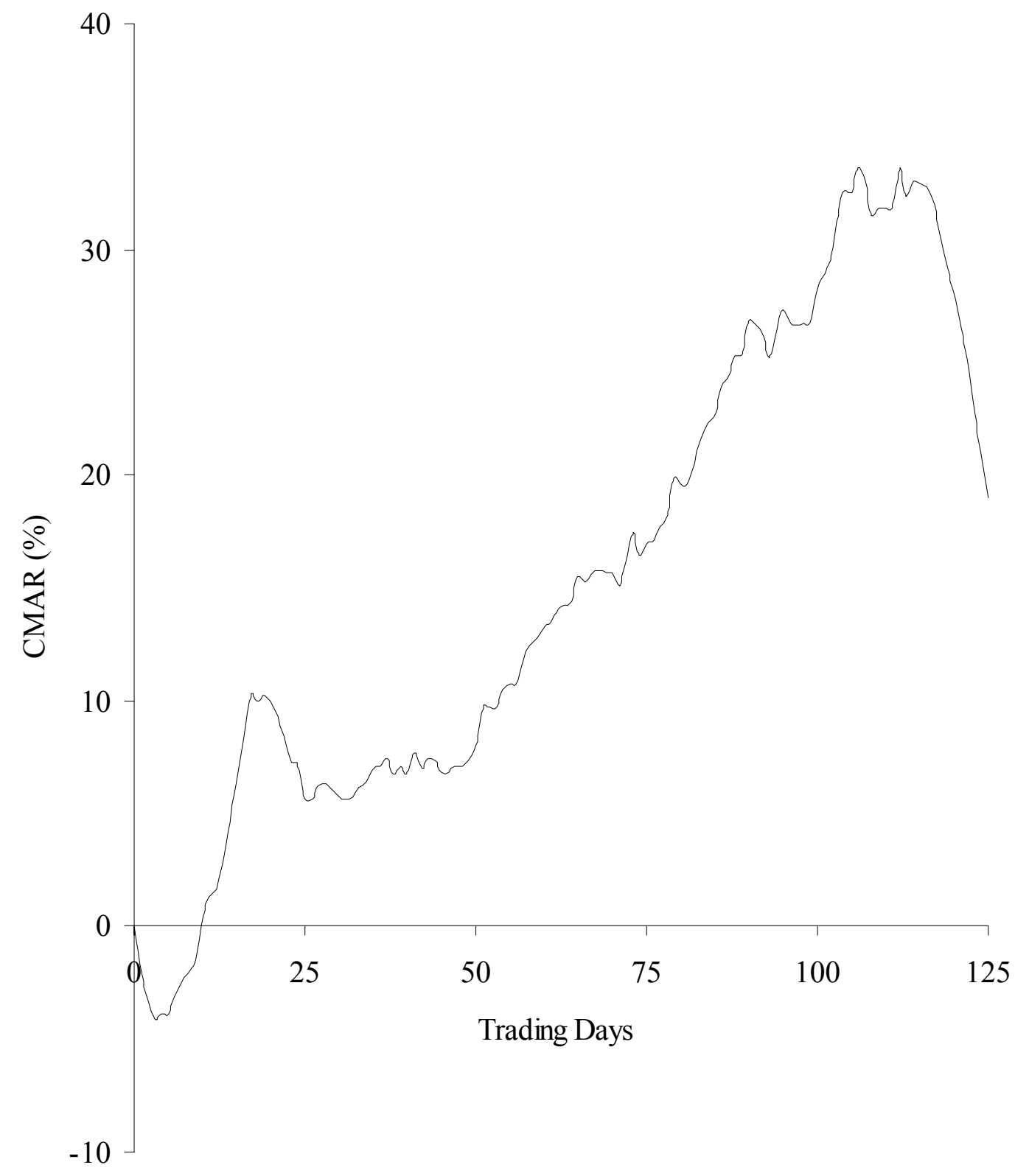

The graph represents performance of an equally-weighted event time CMAR portfolio comprising all 301 firms. The CMAR measure excludes the initial underpricing run-up and the Day 1 market-adjusted return by creating the portfolio on Day 2. 
Figure 2. Cumulative Market Adjusted Returns for quartile segments formed on the basis of Day 1 Adjusted Return

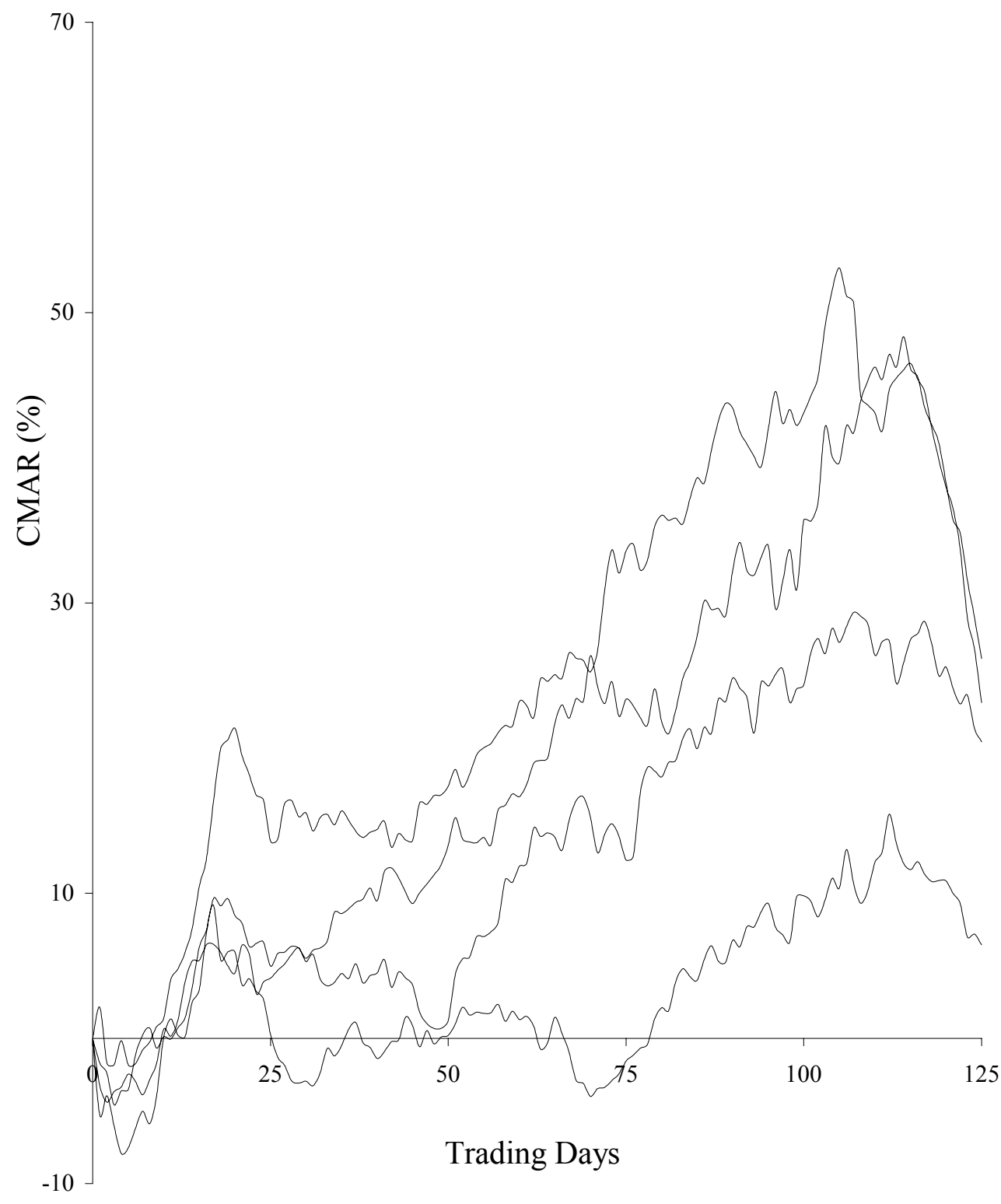

The data are sorted on the basis of day 1 adjusted return to form four equally-weighted event time CMAR portfolios. The portfolios vary consistently on the basis of day 1 adjusted return with the top (bottom) graph representing the top (bottom) quartile segment. As in Figure 1, the CMAR measure excludes the initial underpricing run-up and the Day 1 market-adjusted return by creating the portfolio on Day 2 . 